\title{
Cyclic Nucleotide Structural Differentiation of Compounds Modulating Apoptosis and Drug Resistance
}

\author{
Wynford Robert Williams \\ Faculty of Life Sciences \& Education, University of South Wales, Cardiff, UK \\ Email: robert.williams2@southwales.ac.uk
}

How to cite this paper: Williams, W.R. (2021) Cyclic Nucleotide Structural Differentiation of Compounds Modulating Apoptosis and Drug Resistance. Journal of Biosciences and Medicines, 9, 10-28. https://doi.org/10.4236/jbm.2021.98002

Received: June 1, 2021

Accepted: August 1, 2021

Published: August 4, 2021

Copyright $\odot 2021$ by author(s) and Scientific Research Publishing Inc. This work is licensed under the Creative Commons Attribution International License (CC BY 4.0).

http://creativecommons.org/licenses/by/4.0/

\section{(c) (i) Open Access}

\begin{abstract}
Carcinogenesis is associated with malfunction in the cGMP-mediated regulation of cytosolic $\mathrm{Ca}^{2+}$ and reactive oxygen species. Chemotherapy resistant cancer cells are re-sensitised to apoptosis by the action of a substantial number of natural compounds on cell membrane multidrug resistant proteins. Chemical structures of pro-apoptotic and anti-apoptotic compounds demonstrate relative molecular similarity to cGMP. This study uses a computational chemistry program to investigate molecular similarity within cGMP and chemo-preventative structures. Chemotherapeutic drugs and resistance modulators provide multiple fits to a nucleotide template that differ in their relationship to the cyclised ring of cGMP. The alternative fits of drug and modulator structures may relate to the development and unblocking of apoptosis and drug resistance.
\end{abstract}

\section{Keywords}

Cancer, Chemotherapy, Guanosine Cyclic Monophosphate, Molecular Similarity, Multidrug Resistance

\section{Introduction}

Abnormalities in cancer cell biochemistry are evident in the areas of oxidative stress and store-operated calcium entry (SOCE) associated with malfunctioning mitochondria and endoplasmic reticulum (ER) organelles [1] [2]. These abnormalities accompany deregulation of cyclic nucleotide signaling and cell membrane transport [3] [4]. The research literature describes a central role for the NO-cGMP protein kinase (PKG) pathway in the development and survival of cancer cells: gastric carcinogenesis is linked to activation of the PKG pathway 
[5]. However, PKG pathway components are characterised by dual effects on cancer cells. Several clinical studies have identified extracellular cGMP as a marker of various cancers [3] [6] although in vitro work suggests that cancer-enhancing effects of the nucleotide are concentration dependent. Elevated cGMP levels in breast and colon cancer cell lines induce growth inhibition and apoptosis [7] [8] but basal levels are cytoprotective for unstressed neural and ovarian cancer cells [9] [10].

Cellular cGMP levels are regulated by guanylate cyclase and phosphodiesterase (PDE) activity. Hormonal activation of soluble guanylate cyclase (sGC) is impaired in glioma tissue and breast cancer cells [11] [12]. Suppression of sGC in ovarian and cervical cells augments cell death but is dependent on the subunit composition of the enzyme [13]. PDE5 expression is higher than normal in prostate tumours and PDE5 inhibitor use is associated with cell apoptosis and a lower incidence of colorectal cancer [14] [15]. PDE inhibitors, such as sildenafil, further increase cellular cGMP by inhibiting efflux of the nucleotide from cells [16].

Chemotherapy eliminates cancer cells through promoting irreversible mitochondrial damage or the innate ability of cells to self-destruct via ligand-targeted cell membrane receptors [17]. In practice, the potential of chemotherapy for reducing tumor burden is blunted by the development of drug resistance. Molecular transporters within cell membranes, primarily $\mathrm{ABC}$ transport proteins, export ions and biochemicals, including cyclic nucleotides, through conformational changes initiated by ATP hydrolysis [18]. ABC transporters of chemotherapeutic drugs, defined as multidrug resistant proteins (MRPs), contribute to drug resistance [18]. Chemotherapy may cause further complications by promoting the expansion of resistant cells to the detriment of treatment [19]. There is considerable interest in the development of drugs and natural products that ameliorate drug resistance to maximise the benefits of chemotherapy [20] [21].

Many compounds relate to cGMP in respect of molecular similarity and functional properties. CGMP inhibits SOCE activating mechanisms and molecular similarity is evident in SOCE modulators that promote apoptosis in cancer cell lines [22]. Of 40 apoptosis-inducing compounds demonstrating relative molecular similarity to cGMP, 70\% also provide protection against apoptosis [22]. Specific anti-apoptic properties are characteristic of folic acid, vitamin $\mathrm{E}$ and phytic acid. Apoptosis-inducing properties are therefore common but more puzzling are the capacities of compounds to both induce and prevent apoptosis. The CheBI (Chemical Entities of Biological Interest) database of over 58,000 small compounds lists 263 inducers and 50 inhibitors of apoptosis. Many of the inhibitors, however, have references appended to their data sheets providing evidence of apoptosis initiation. Further work on structural relationships within apoptosis-modulating compounds and guanosine cyclic nucleotide should contribute to a better understanding of cancer development and treatment. This investigation uses a molecular modeling approach to search for similarity in the 
structures of apoptosis modulators, chemotherapeutic drugs, and inhibitors and substrates of MRPs.

\section{Methods}

\subsection{Selection of Compounds}

Compound structures are from Pubchem (https://pubchem.ncbi.nlm.nih.gov/), CheBI (http://www.ebi.ac.uk/) and IUPHAR databases [23]. Natural chemotherapeutic agents and drug resistance modulators are identified in Wang et al. [20] and Redondo-Bianco et al. [24] respectively. Drugs targeting specific multidrug resistance proteins are listed in Wang et al. [21]. Substrates and inhibitor compounds of the breast cancer resistance protein (ABCG2) are found in Mao and Unadkat [25].

\subsection{Molecular Modeling}

The Nemesis software program (Oxford Molecular version 2.1) is used to build molecular structures from contents of the program fragment file and minimise structures by conformational analysis. Compound structures used in fitting are minimum energy conformers in an uncharged form. The conformation of cGMP is described by the torsion angle $\mathrm{C} 8 \mathrm{~N} 9 \mathrm{Cl}^{\prime} \mathrm{O} 9-33^{\circ}$ (see Figure 1). The computational program fits paired molecular structures on a three-point basis. Fitting-points, comprised of atoms of similar type and partial charge within compound and nucleotide structures, are identified in the text with respect to the nucleotide labels. Colour-coded atoms in the Figures identify ligand fitting-points: carbon-green, nitrogen-blue, oxygen-red, sulphur-yellow. To improve on presentation, bond order within the molecular structures is not shown. The Nemesis program computes goodness-of-fit values, in respect of inter-atomic distance at each fitting-point and root mean square (RMS) value.

\section{Results}

\subsection{Apoptosis Inhibitors and Chemotherapeutic Agents}

Figure 1 displays the minimum energy structures of identified apoptosis inhibitors with their fits to a cGMP template (1). Most of these compounds are of plant origin, whereas bonkrekic acid is a toxic microbial metabolite. Compound structures 4, 5 and 7, based respectively on pteridin, chromenol and coumarin ring systems, fit to the ribose-cyclic-phosphate moiety of cGMP. The fits of structures 2, 3, and 6, incorporating dithiolane, cyclohexyl and hydroxyphenyl rings, are confined to the dioxaphosphinine ring. Carboxylic acid and sulphate residues participate in the fits of structures $9-11$ and these have at least one fitting-point on the nucleotide purine ring. The fits of two steroid structures, 17 - $\beta$-estradiol [12] [13] and progesterone [14] are given for comparison. Goodness of fit values of the 11 inhibitors range from 0.02 - $0.12 \AA$ (interatomic distance) and 0.0009 - $0.0221 \AA$ (RMS). Chemotherapeutic drug structures (Figure 2) give alternative fits in relation to the ribose-cyclic-phosphate moiety, in a 

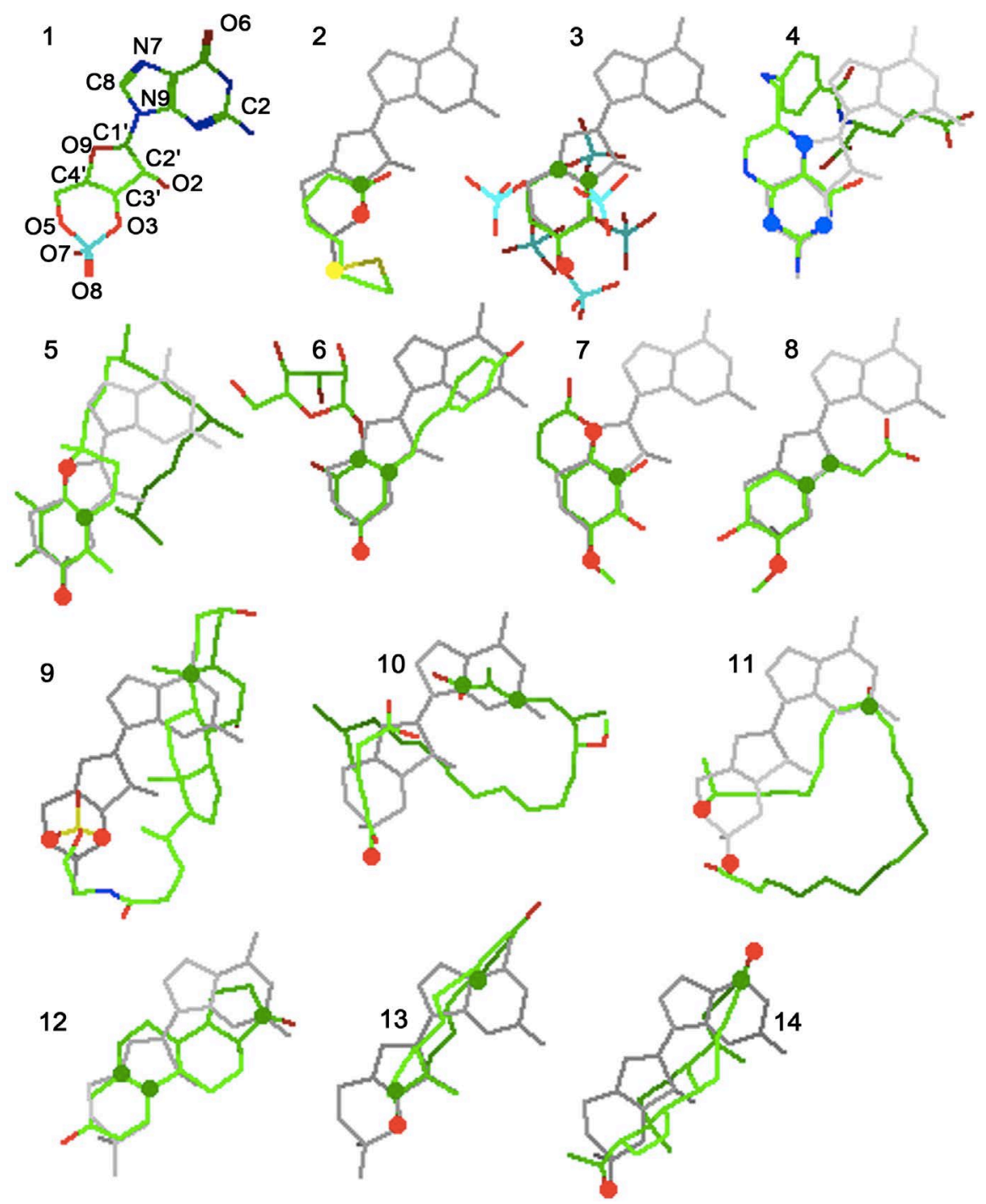

Figure 1. Apoptosis inhibitors: fits of structures to cGMP template (grey). 1 cGMP; 2 alpha-lipoic acid; 3 phytic acid; 4 folic acid; 5 vitamin E; 6 tetrahydroxystilbene glucoside; 7 fraxetin; 8 ferulic acid; 9 taurosocholate; 10 bongkrekic acid; 11 dihydroxydocosaenoic acid; 12 and 13 17- $\beta$-estradiol; 14 progesterone.

similar manner to estradiol; each providing a template fit that blocks the terminal cyclized ring of cGMP and another that is less obstructive. The more simple drug structures (5-fluorouracil, oxiplatin, gemcitabine, tamoxifen) provide fitting-points on the ribose-cyclic-phosphate moiety, whereas the fitting-points of larger structures (doxorubicin, DS-8201a, paclitaxel, mertansine, retinoic acid) are also present on the nucleotide base. The dioxaphosphinine ring blocking-fit of methotrexate [12] is the same as the folate structure. Goodness of fit values $(\mathrm{n}=20)$ of the chemotherapeutic drugs range from $0.01-0.15 \AA$ (interatomic distance) and $0.0009-0.0248 \AA$ (RMS).

\subsection{Resistance Modulators}

The compounds given in Figure 3 and Figure 4 display the same range of 

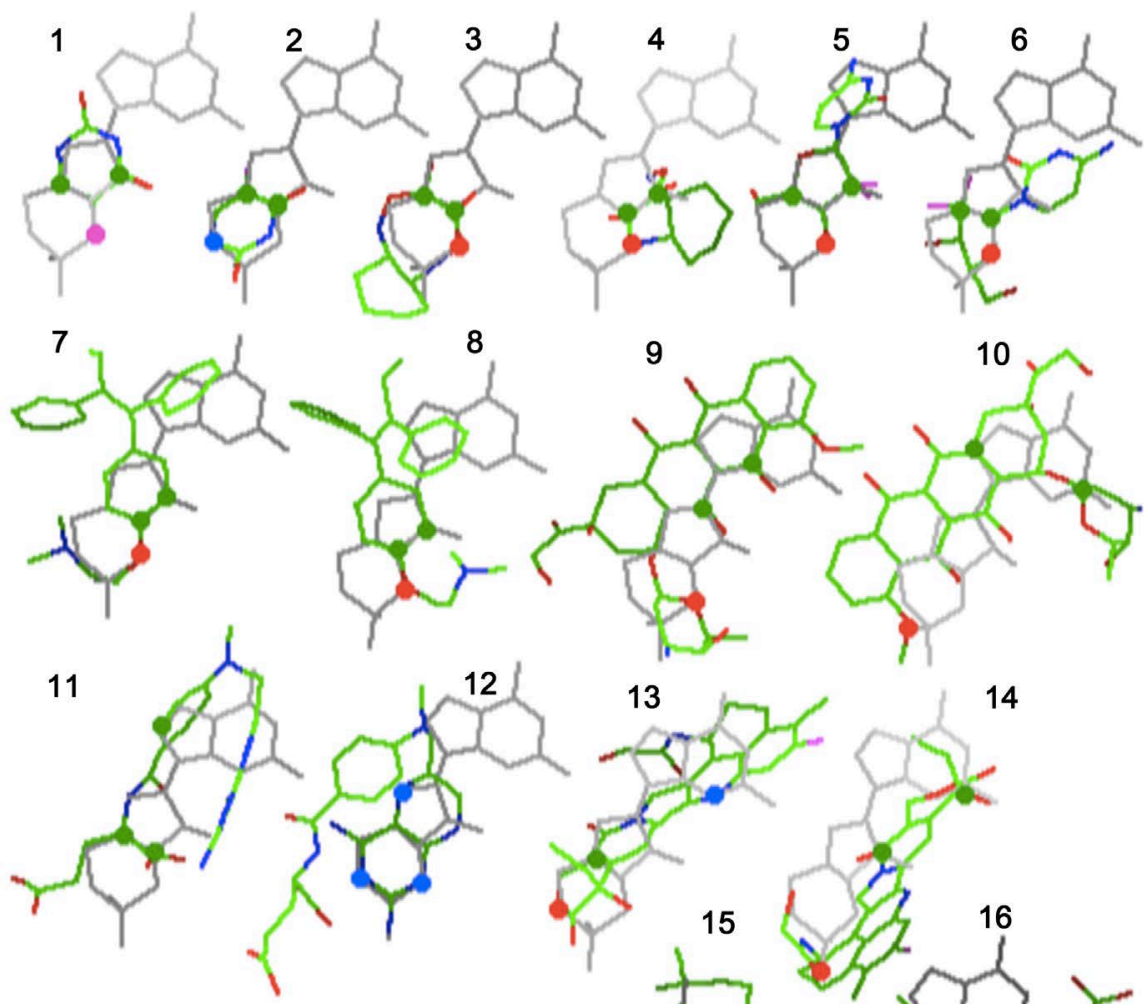

14

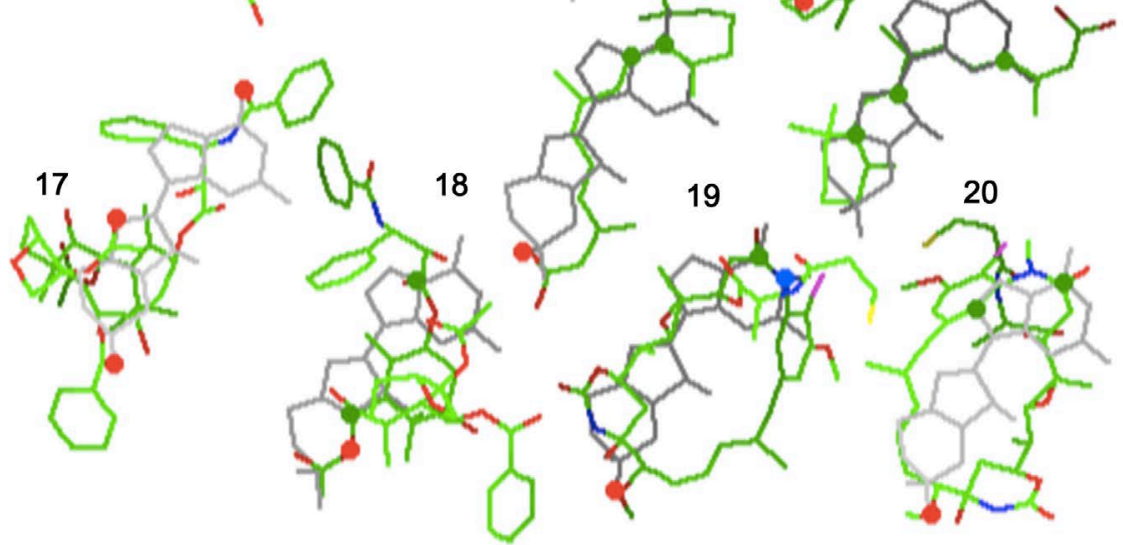

Figure 2. Chemotherapeutic drugs: fits of structures to cGMP template (grey). 1 and 2 5-fluorouracil; 3 and 4 oxiplatin; 5 and 6 gemcitabine; 7 and 8 tamoxifen; 9 and 10 doxorubicin; 11 and 12 methotrexate; 13 and 14 DS-8201a; 15 and 16 retinoic acid; 17 and 18 paclitaxel; 19 and 20 mertansine.

structural diversity, molecular size and multiple fits to the cGMP template as the compounds in Figure 2. Fitted molecular structures again demonstrate occlusion and non-occlusion of the nucleotide dioxaphosphinine ring. Some of the best examples of duality are given by the more complex structures in Figure 3: tanshinone, carnosic acid, schisandrin, and dihydroartemisinin. Benzofuran and benzomethoxy groups are significant in the fits of tanshinone, psoralen, curcumin and schisandrin. Endocyclic oxygen and nitrogen atoms contribute to the fitting-points in other structures. Several fits are shown for the pyrazine ring of ligustrazine [5] [11]. Gingsenoside and epigallocatechin, verbascoside, baicalin, peiminine, dauricin and tetrandrine (Figure 4) have a higher mass than cGMP; 


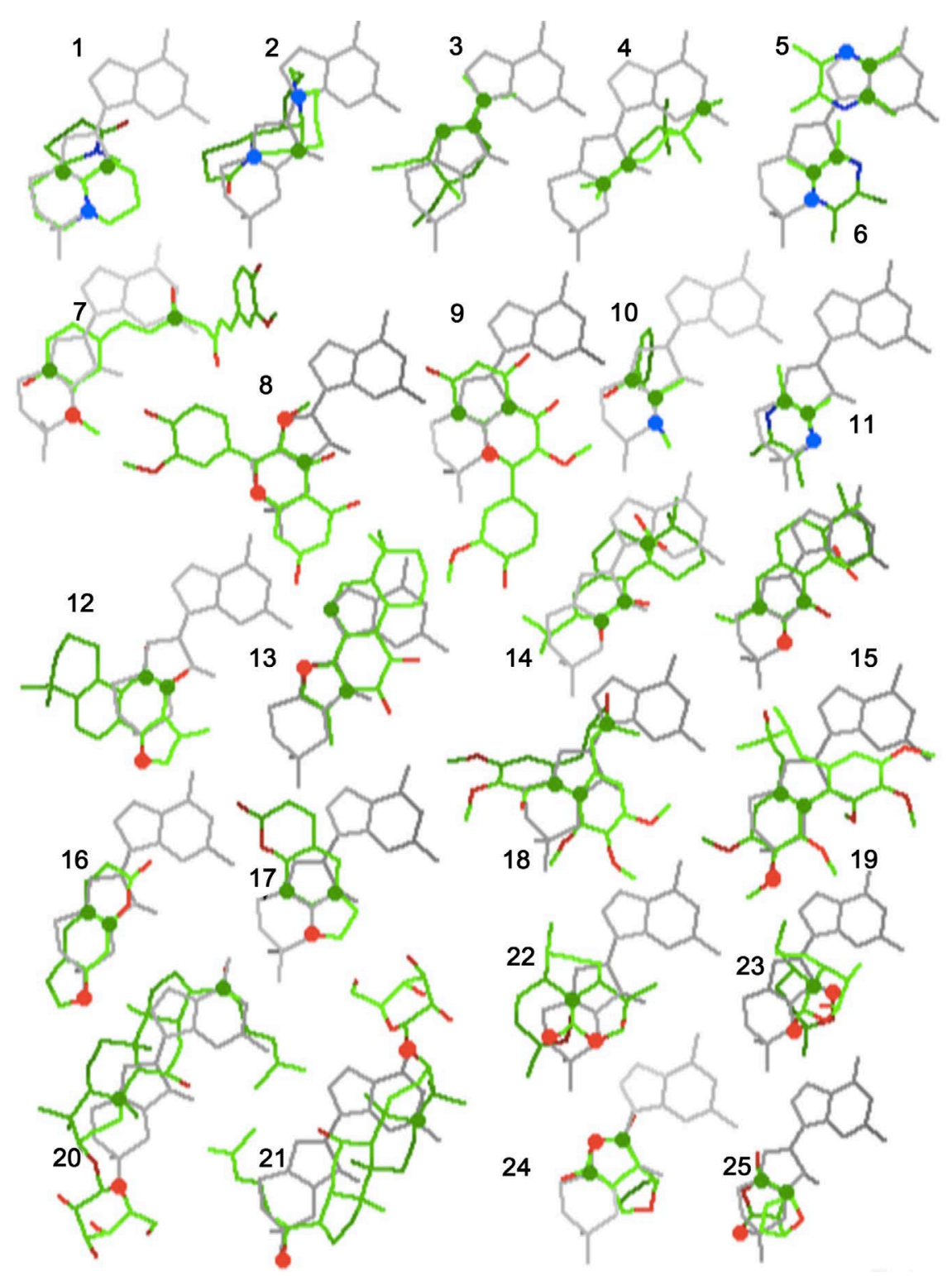

Figure 3. Chemotherapy resistance inhibitors: fits of structures to cGMP template (grey) 1 and 2 matrine; 3 and $4 \delta$-elemene; 5 and 6 ligustrazine; 7 curcumin; 8 and 9 dimethylquercetin; 10 ephedrine; 11 ligustrazine; 12 and 13 tanshinone; 14 and 15 carnosic acid; 16 and 17 psoralen; 18 and 19 schisandrin, 20 and 21 gingsenoside; 22 and 23 dihydroartemisinin; 24 and 25 norcantharidin.

the latter two are dimeric structures. Sugar residues of verbascoside [9] [10], baicalin [13] [14] and gingsenoside contribute to the nucleotide template fits. Uncommon fitting groups within these compounds include the benzodioxolo ring of berberine and the methoxypropenoate side-chain of isorhynchophylline. The fitting data demonstrates that the inclusion of $\mathrm{O} 5$ within a fitting-point set is more likely to define a ring-blocking structure than an $\mathrm{O} 3, \mathrm{O} 7$ or $\mathrm{O} 8$ fitting-point. Goodness of fit values of Figure 3 and Figure 4 structures $(n=43)$ range from $0.01-0.18 \AA$ (interatomic distance) and $0.0001-0.0171 \AA$ (RMS).

Figure 5 gives a range of template fits for the flavone and isoflavone class 


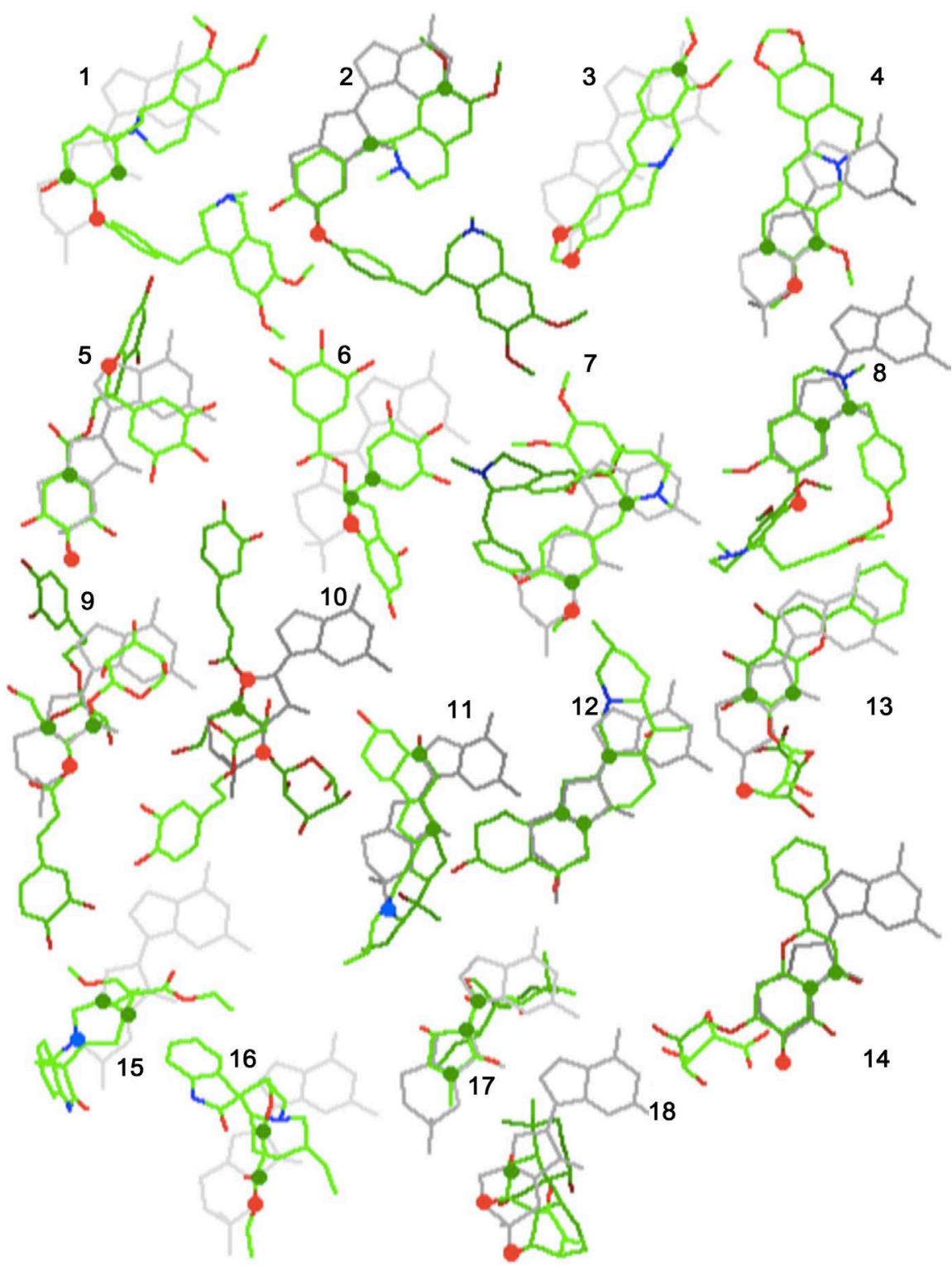

Figure 4. Chemotherapy resistance inhibitors: fits of structures to cGMP template (grey) 1 and 2 dauricin; 3 and 4 berberine; 5 and 6 epigallocatechin; 7 and 8 tetrandrine; 9 and 10 verbascoside; 11 and 12 peiminine; 13 and 14 baicalin; 15 and 16 isorhynchophylline; 17 and 18 oridonin.

structures (1 - 6). The fits of resveratrol [7] [8], vitamin D [9] [10], sapitinib [13] and verapamil [15] [16] are conventional in their use of phenoxy, cyclohexanol and methoxybenzene groups. In contrast, those of bromocriptine [11], triptolide [12], selinexor [14] and midostaurine [17] are substantially different. The midostaurin structure provides four similar fits to the nucleotide template, of which only one is shown. The nucleotide fitting-points most commonly shared by compounds incorporate oxygen O3: O3C2'C4' $(\mathrm{n}=10)$, O3C3'C4' $(\mathrm{n}=4)$, O3C3'C2' ( $\mathrm{n}=3)$. The latter set accommodates the BMM structure (butyl-2methyl-malonic acid) [19], a compound that has found use as a radioactive marker of apoptosis following chemotherapy. The fitting-points of ML-9 [20] 


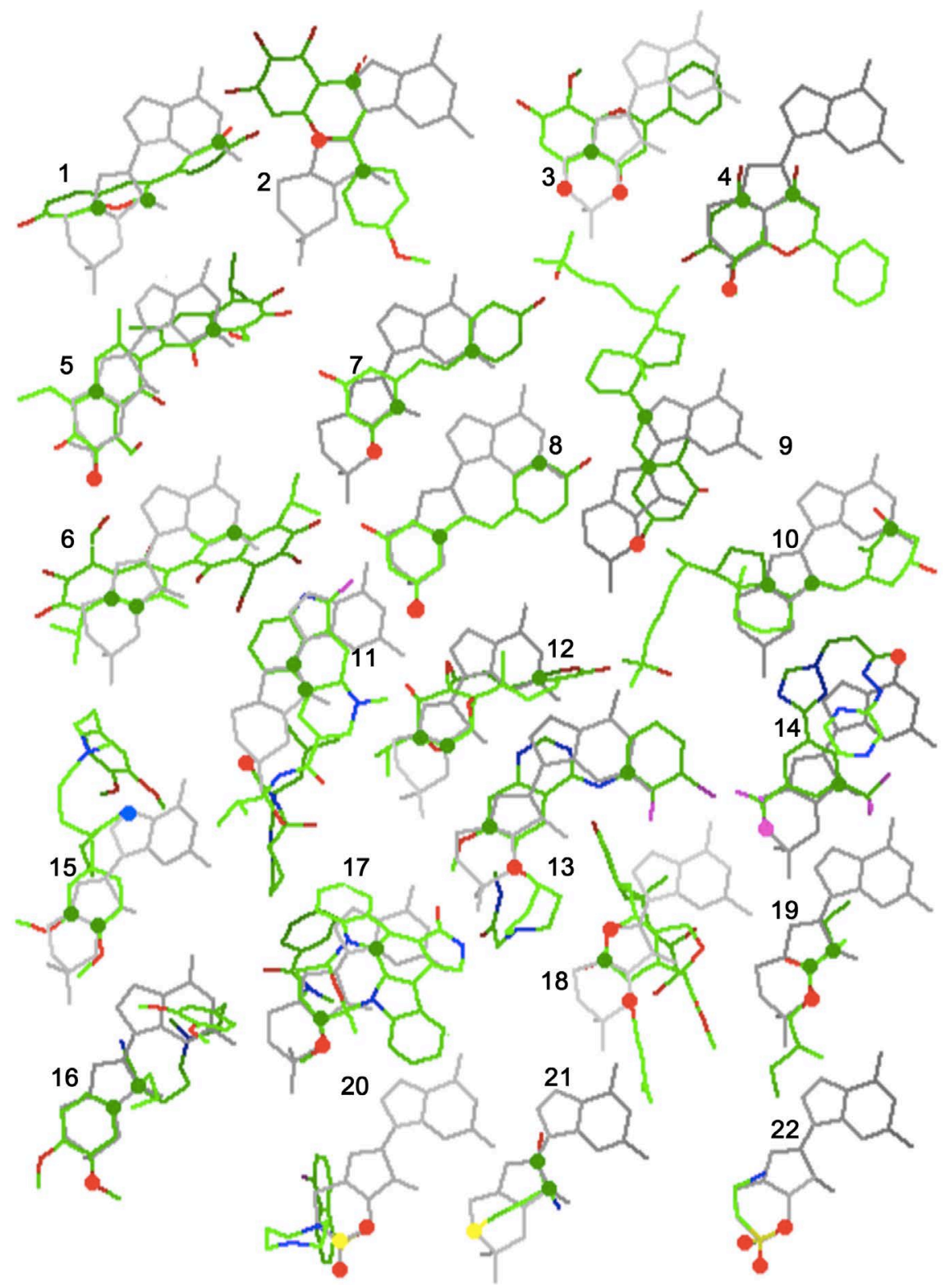

Figure 5. Chemotherapy resistance inhibitors: fits of structures to cGMP template (grey). 1 7,4,4-THF; 2 scutellarein; 3 and 4 wogonin; 5 and 6 gossypol; 7 and 8 resveratrol; 9 and 10 vitamin D; 11 bromocriptine; 12 triptolide; 13 sapitinib; 14 selinexor; 15 and 16 verapamil; 17 midostaurin; 18 brusatol; 19 BMM; 20 ML-9; 21 homocysteine; 22 taurine.

and taurine [22] target the same site and differ from those of the other sulphur containing amino acid, homocysteine [21]. Goodness of fit values for Figure 5 structures $(\mathrm{n}=22)$ range from $0.02-0.14 \AA$ (interatomic distance) and 0.0007 $0.0227 \AA$ (RMS).

Figure 6 [1]-[7] displays the modulating agents of multidrug resistance proteins (MRP 1-5 and MRP7). The structures superimpose on the cGMP template with one fitting-point (C2) in common. MRP1 modulators, TAK 733 and 8-prenylnaringenin, share the same fitting-points that place pyridopyrimidine and benzopyran rings at right angles to the guanine ring. Otherwise, there is no 


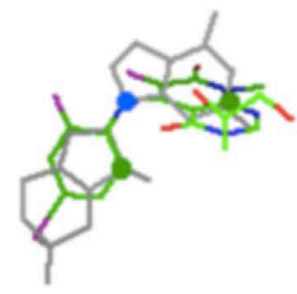

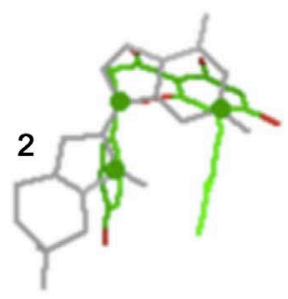
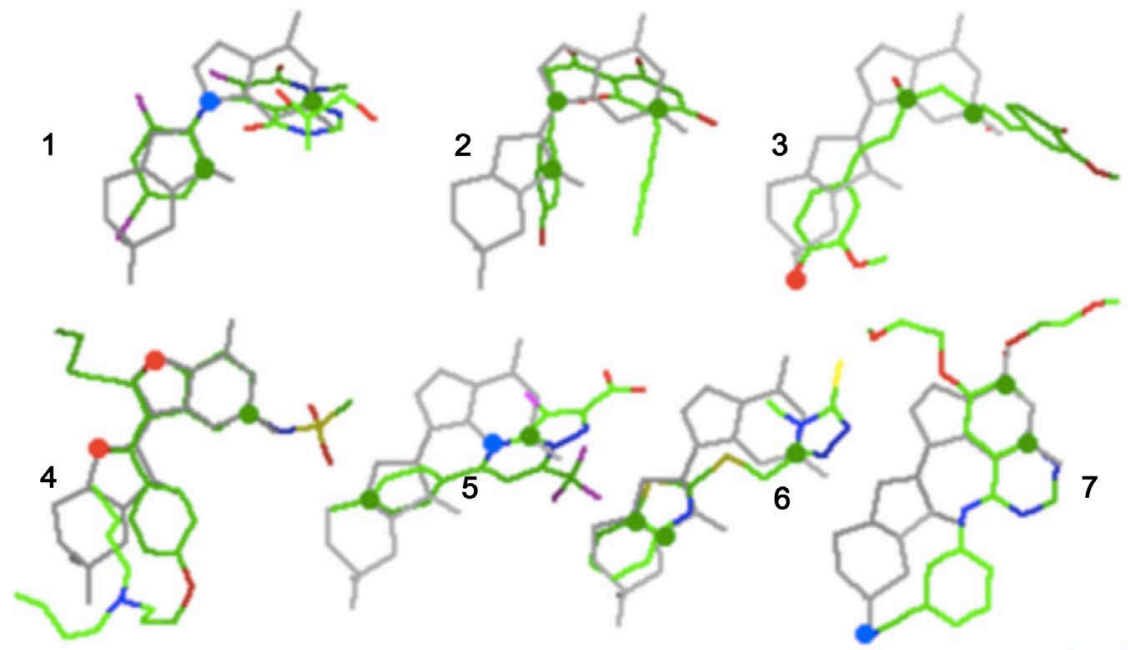

\section{7}
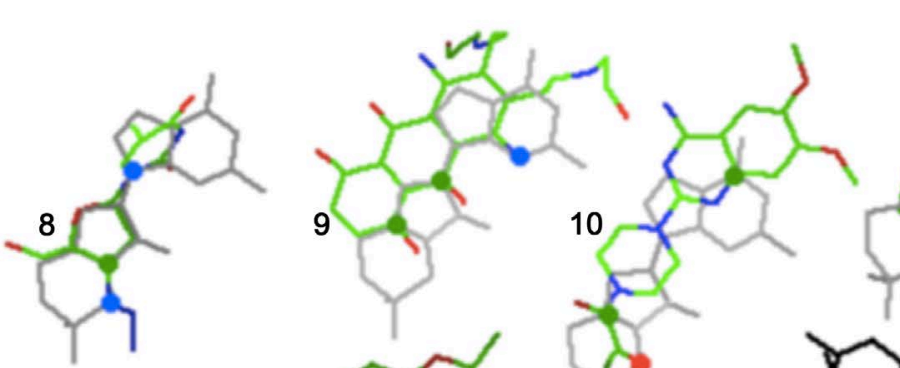

11

12
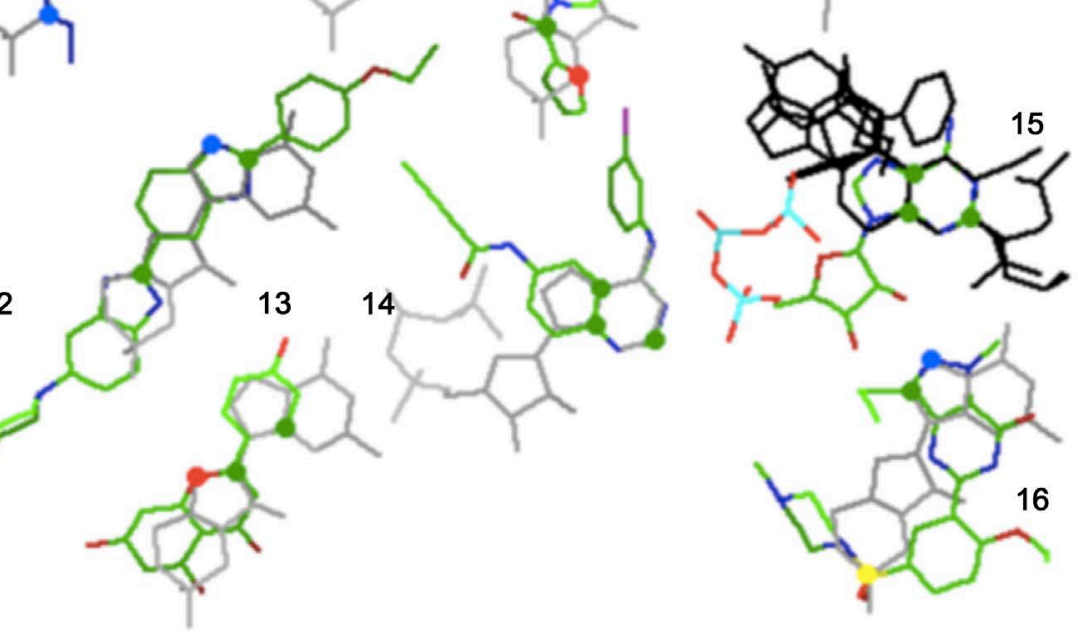

Figure 6. Modulators of multidrug resistance proteins (1 - 7), substrates and inhibitors of ABCG2 protein (8 - 15). Fits of structures (1 - 13) to cGMP (grey), (14) to ATP (grey). 1 TAK 733; 2 8-prenylnaringenin; 3 curcumin; 4 dronedarone; 5 ceefurin-1; 6 ceefurin-2; 7 eriotinib; 8 AZT; 9 mitoxantrone; 10 prazosin; 11 estrone sulphate; 12 bisbenzamide; 13 genistein; 14 EK1-785; 15 showing composite fit of diethylstilbestrol, tamoxifen, febuxostat and estrone to ATP template; 16 sildenafil.

consistent arrangement of fitting-points for the structures of the MRP modulator classes. Templates 8 - 13 give the fits of breast cancer resistance protein (ABCG2) substrates that include an alpha-receptor blocker [10] and fluorescent dye (12). Fitted structures lie in the same plane along the axis of cGMP with no consistent blocking of the dioxaphosphinine ring. Templates 14 and 15 identify fitting-points for ABCG2 inhibitors on the purine ring of ATP, the latter template being a composite image of 4 superimposed structures (diethylstilbestrol, 
tamoxifen, febuxostat, estrone) that reveals a high density of cyclic ring and alkyl chain substituents above the nucleotide triphosphate chain. Goodness of fit values of template structures 1-13 range from $0.02-0.12 \AA$ (interatomic distance) and $0.0016-0.0144 \AA$ (RMS). The values for template 14 and 15 inhibitors are $0.02 \AA$ and $0.0000 \AA$. The fit of the PDE antagonist sildenafil [16] involves the imidazole moiety and dioxaphosphinine ring of cGMP (0.09- $0.11 \AA$, $0.0078 \AA$ ).

\section{Discussion}

Of the three specific apoptosis inhibitors identified in a previous study, phytic acid must now be considered as having dual properties, in view of reported apoptosis action on HepG2 carcinoma cells [26]. The phytic acid structure provides an alternative fit at $\mathrm{C}^{\prime} \mathrm{C} 3^{\prime} \mathrm{O} 3$ (not shown) in keeping with other apoptosis-inducing structures in Figure 2. Ferulic acid and fraxetin are listed as inhibitors on the ChEBI database but there are also reports of apoptosis initiation [27] [28]. In this respect, ferulic acid is able to give the same fit as its parent compound, curcumin (Figure 3 ) and fraxetin provides the same template fit as psoralen (Figure 3). Tauroursodeoxycholate, a bile acid, alleviates ER stress and apoptosis in adrenocortical carcinoma cells [29]. The lipids, bongkrekic and dihydroxydocosaenoic acids resist apoptosis in HeLa and mesenchymal stem cells respectively [30] [31]. In regard to the dual template fits of apoptosis modulators to the cGMP template, the anti-apoptosis mode may be represented by dioxaphosphinine ring occlusion as in the occluded fits of vitamin $\mathrm{E}$ and 17- $\beta$-estradiol structures. Endogenous compounds that should be given consideration as apoptosis inhibitors include steroid hormone and nucleotide structures. The efflux of cGMP from a squamous carcinoma cell line is stimulated by progesterone [32]. Lewis-Wambi and Jordan [33] question how estrogen is able to both stimulate and inhibit apoptosis. The answer may relate to relative molecular similarity within the estrogen structure that permits the steroid to substitute for the ribose-cyclic-phosphate moiety of cGMP in different ways. The dual fits of estrogen to the cGMP template are explored in other structures that modulate apoptosis.

Chemotherapeutic agents have various cellular targets and activate different pathways in which caspases play a critical role [34]. Compounds DS-8201a and mertansine are the active constituents of newer antibody-drug conjugates, developed to target human epidermal growth factor receptors and reduce resistance. Both drugs are potent apoptosis inducers [35] [36]. In common with chemotherapeutic drugs, resistance inhibitor structures demonstrate multiple fits to the nucleotide template with diverse sets of fitting-points. There is no exact equivalence between the fitting-points of doxorubicin and those of the 15 natural compounds listed as agents that overcome doxorubicin drug resistance [20]. Most of these compounds share one or two fitting-points with doxorubicin but baicalin has none. The relationship between the impact of these drugs on doxorubicin resistance and their relative molecular similarity to the cGMP 
structure is more likely expressed through functional effects on a cGMP binding-protein, via interaction with receptor-binding sites, or allosteric modulation of conformational changes.

Apoptosis modulating flavonoid compounds such as trihydroxyisoflavone, wogonin and brusatol are known to increase ROS or inhibit Nrf2 transcription factor regulation of anti-oxidant proteins [37] [38] [39]. Combinations of natural apoptosis modulating agents (gossypol, resveratrol, genistein, quercetin, EGCG, triptolide, curcumin, resveratrol, methylether-scutellarein) with chemotherapeutic drugs have shown synergistic apoptosis induction in vitro, thereby improving strategies for targeting drug resistance [24] [40] [41] [42]. In this context, the multi-kinase inhibitor midostaurin has already found clinical use [43]. The fits of vitamin D to the cGMP template can be related to reports of guanylate cyclase activation, modulation of SOCE and induction of tumour senescence through inhibition of oxidative stress [44] [45] [46]. Verapamil has a dual action on apoptosis; reducing mitochondrial damage, oxidative stress and apoptosis in the pre-frontal cortex of rats but triggering apoptosis of kidney hamster cells through stimulation of glutathione extrusion via the MRP1 transporter [47] [48]. Verapamil also causes competitive, concentration dependent, inhibition of cGMP transport in human erythrocyte vesicles [49]. The unusual template fit of ML-9 is in keeping with the complex properties of this compound that include the induction of apoptosis and autophagy in some cancer cell lines, enhancement of chemotherapy, and antagonism of SOCE, ROS, ER stress and apoptosis [50] [51]. The sulphur containing amino acids homocysteine and taurine occupy different positions in the health spectrum. The former compound increases ROS and anti-oxidant activity in vitro and is particularly associated with gastric cancer [52], whereas the latter antagonises the in vitro effects of homocysteine [53].

Cancer cell resistance to chemotherapy relates to lipid changes within the cell membrane and the processes that govern drug entry and exit [4]. The best studied of the $A B C$ drug transporter proteins include the ABCG2 protein and isoforms of the MRP that share structural and mechanistic features common to transmembrane and nucleotide-binding domains (NBDs) [21]. The MRP1 bipartite binding site for leukotriene $\mathrm{C} 4$ has recently been described in detail [54]. Substrate binding introduces local and global conformational changes, followed by dimerization of the NBDs and activation of the catalytic site to hydrolyse ATP. The interacting receptor residues of the binding site demonstrate adaptability of the receptor to a variety of substrates [54]. In this study, all modulator compounds of the MRP isoforms demonstrate molecular similarity relative to cGMP. Zloh et al. [55] reported on the results of a molecular modelling study that identified affinities between multidrug resistance inhibitors and chemotherapeutic drugs. The authors attributed their findings to the formation of drug-inhibitor complexes that impacted on transporter mechanisms. The present findings make it more likely that the common properties of inhibitors (such as verapamil and tetrandrine) reported by Zloh et al. [55] relate to cGMP-based 
molecular similarity.

The ABCG2 protein also has a large and broad substrate range: therapeutics, common dietary xenobiotics, environmental toxins, metabolites and vitamins [56]. The size of the central substrate cavity supports the concept of binding zones, rather than a well-defined binding site, with the possibility of cooperative binding and allosteric modes of action. Inhibitors of ABCG2, such as fumitremorgin and Ko143, are considered to be general inhibitors because they inhibit the ATPase activity [25]. On this account, and based on the observation that the ABCG2 inhibitors (Figure 6) show no nucleotide preference for fitting, their simple and general fits are demonstrated using an ATP template. Relative molecular similarity within the compounds investigated in this study is not solely guanine-base specific. cAMP-induced apoptosis is particularly evident in haematological malignancies [57] [58]. Both cyclic nucleotides inhibit store-operated $\mathrm{Ca}^{2+}$ channels via protein kinases [59] and are structurally similar in their imidazole and ribose-cyclic-phosphate moieties.

The PDE inhibitor sildenafil enhances cancer cell apoptosis and chemotherapeutic outcome [60] [61] through increasing cGMP levels and inhibiting cGMP efflux transporters [62] [63]. Blockage of cGMP efflux by sildenafil results from structural similarity to the nucleotide, an indication that sildenafil may be capable of replacing cGMP in some functional processes. Although it is natural to assign the benefits of PDE inhibitors to their best-established property, alternative anti-oxidant effects may be as important in facilitating cancer therapy. Sildenafil has ROS reducing benefits, contributing to cell redox homeostasis, and alters basal $\mathrm{Ca}^{2+}$ by down-regulating the TRPC proteins of store-operated calcium channels [64] [65] [66]. ML-9 is another relevant compound that inhibits STIM1 function and SOCE [67]. Some properties of sildenafil and ML-9 may relate to proxy action on behalf of cGMP, as the nucleotide is a molecular link in the various processes involved in cytosolic $\mathrm{Ca}^{2+}$ regulation. $\mathrm{Ca}^{2+}$ entry via cGMP activation of cyclic nucleotide-gated channels contributes to mouse rod photoreceptor apoptosis [68]. cGMP inhibits the actions of cyclopiazonic acid and thapsigargin on SOCE [22] and matrix metalloproteinase release implicated in raising the invasive potential of hepatocellular carcinoma cells [69]. Basal levels of cGMP may prevent the development of apoptosis by contributing to the stability of cell membranes [9] [70]. ER stress is suppressed in pancreatic and neuronal cells by increasing NO-cGMP signaling [71] [72]. Increases in cytosolic $\mathrm{Ca}^{2+}$ can, however, trigger the mitochondrial NO/cGMP pathway to induce cytochrome $\mathrm{c}$ release and apoptosis [73].

In considering the link between apoptosis resistance and cancer therapy, Mohammad et al. [40] consider the difficulty in explaining the re-sensitisation of tumor cells (a process requiring a unique and common mechanism) by natural compounds so structurally and functionally different. This study demonstrates that natural compounds and drugs with the property of re-sensitisation have a common characteristic in their relative molecular similarity to cGMP; a compound involved with MRPs and cell-signaling pathways, a target of PDE inhibi- 
tor cancer drugs and modulator of SOCE, ROS and apoptosis. cGMP status is responsive to the physiological changes initiating cancer, as well as the processes impacted by cancer therapy. Research progress in this area may be advanced by further work on the potential for interaction between nucleotides and endogenous lipids and steroid structures displaying relative molecular similarity.

\section{Acknowledgements}

This paper is dedicated to the memory of Laurie J. M. Williams (1955-2021).

\section{Conflicts of Interest}

The author declares no conflicts of interest regarding the publication of this paper.

\section{References}

[1] Redza-Dutordoir, M. and Averill-Bates, D.A. (2016) Activation of Apoptosis Signaling Pathways by Reactive Oxygen Species. Biochimica et Biophysica Acta, 1863, 2977-2992. https://doi.org/10.1016/j.bbamcr.2016.09.012

[2] Tajada, S. and Villalobos, C. (2020) Calcium Permeable Channels in Cancer Hallmarks. Frontiers in Pharmacology, 11, Article No. 968. https://doi.org/10.3389/fphar.2020.00968

[3] Fajardo, A.M., Piazza, G.A. and Tinsley, H.N. (2014) The Role of Cyclic Nucleotide Signaling Pathways in Cancer: Targets for Prevention and Treatment. Cancers, 6, 436-458. https://doi.org/10.3390/cancers6010436

[4] Assaraf, Y.G., Brozovic, A., Goncalves, A.C., Jurkovicova, D., Line, A., Machuqueiro, M., Saponara, S., Sarmento-Ribeiro, A.B., Xavier, C.P.R. and Vasconcelos, M.H. (2019) The Multi-Factorial Nature of Clinical Multidrug Resistance in Cancer. Drug Resistance Updates, 46, Article ID: 100645. https://doi.org/10.1016/j.drup.2019.100645

[5] Xiang, T., Yuan, C., Guo, X., Wang, H. Cai, Q., Xiang Y., Luo, W. and Liu, G. (2021) The Novel ZEB1-Upregulated protein PRTG Induced by Helicobacter pylori Infection Promotes Gastric Carcinogenesis through the cGMP/PKG Signaling Pathway. Cell Death and Disease, 12, Article No. 150. https://doi.org/10.1038/s41419-021-03440-1

[6] Orbo, A., Hanevik, M., Jaeger, R., Van Heusden, S. and Sager, G. (2007) Urinary Cyclic GMP after Treatment of Gynecological Cancer. A Prognostic Marker of Clinical Outcome. Anticancer Research, 27, 2591-2596.

[7] Ikeda, M., Ishima, Y., Chuang, V.T.G., Ikeda, T., Kinoshita R., Watanabe, H., Ishida, T., Otagiri, M. and Maruyama, T. (2017) Apoptosis Induction of Poly-S-Nitrosated Human Serum Albumin in Resistant Solid Tumor under Hypoxia Can Be Restored by Phosphodiesterase 5 Inhibition. Nitric Oxide, 69, 28-34.

https://doi.org/10.1016/j.niox.2017.04.005

[8] Wood, K., Donnenwirth, R., Mills, K. and Tinsley, H.N. (2019) Cyclic GMP Signaling during Human Lactation and Breast Cancer: Implications for Breast Cancer Prevention. Breast Journal, 25, 775-777. https://doi.org/10.1111/tbj.13339

[9] Wong, J.C. and Fiscus, R.R. (2011) Essential Roles of the Nitric Oxide (NO)/GMP/ Protein Kinase G-Type- $1 \alpha$ (PKG-1 $\alpha$ ) Signaling Pathway and the Atrial Natriuretic Peptide (ANP)/cGMP/PKG1 $\alpha$ Autocrine Loop in Promoting Proliferation and Cell 
Survival of OP9 Bone Marrow Stromal Cells. Journal of Cellular Biochemistry, 112, 829-839. https://doi.org/10.1002/jcb.22981

[10] Fraser, M., Chan, S.L., Chan, S.S.L., Fiscus, R.R. and Tsang, B.K. (2006) Regulation of p53 and Suppression of Apoptosis by the Soluble Guanylyl Cyclase/cGMP Pathway in Human Ovarian Cancer Cells. Oncogene, 25, 2203-2212. https://doi.org/10.1038/sj.onc.1209251

[11] Bian, K., Ghassemi, F., Sotolongo A., Siu, A., Shauger, L., Kots, A. and Murad, F. (2012) NOS-2 Signaling and Cancer Therapy. IUBMB Life, 64, 676-683. https://doi.org/10.1002/iub.1057

[12] Wen, H.C., Chuu, C.P., Chen, C.Y., Shiah, S.G., Kung, H.J., King, K.L., Su, L.C., Chang, S.C. and Chang, C.H. (2015) Elevation of Soluble Guanylate cyclase Suppresses Proliferation and Survival of Human Breast Cancer Cells. PLOS ONE, 10, e0125518. https://doi.org/10.1371/journal.pone.0125518

[13] Ronchetti, S.A., Pino, M.T.L., Cordeiro, G, Bollani, S.B., Ricci, A. G., Duvilanski, B.H. and Cabilla, J.P. (2019) Soluble Guanylyl cyclase a1 Subunit Is a Key Mediator of Proliferation, Survival, and Migration in ECC-1 and HeLa Cell Lines. Science Reports, 9, Article No. 14797. https://doi.org/10.1038/s41598-019-51420-5

[14] Mei, X.L., Yang, Y., Zhang, Y.J., Li, Y., Zhao, J.M., Qiu, J.G., Zhang, W.J., Jiang, Q.W., Xue, Y.Q., Zheng, D.W., Chen, Y., Qin, W.M., Wei, M.N. and Shi, Z. (2015) Sildenafil Inhibits the Growth of Human Colorectal Cancer in Vitro and in Vivo. American Journal of Cancer Research, 5, 3311-3324.

[15] Huang, W., Sundquist, J., Sundquist, K. and Ji, J. (2020) Phosphodiesterase-5 Inhibitors Use and Risk for Mortality and Metastases among Male Patients with Colorectal Cancer. Nature Communications, 11, Article No. 3191.

https://doi.org/10.1038/s41467-020-17028-4

[16] Subbotina, A., Ravna, A.W., Lysaa, R.A., Abagyan, R., Bugno, R. and Sager, G. (2017) Inhibition of PDE5A1 Guanosine Cyclic Monophosphate (cGMP) Hydrolysing Activity by Sildenafil Analogues That Inhibit Cellular cGMP Efflux. Journal of Pharmacy and Pharmacology, 69, 675-683. https://doi.org/10.1111/jphp.12693

[17] Derakhshan, A., Chen, Z. and Van Waes, C. (2017) Therapeutic Small Molecules Target Inhibitor of Apoptosis Proteins in Cancers with Deregulation of Extrinsic and Intrinsic Cell Death Pathways. Clinical Cancer Research, 23, 1379-1387.

https://doi.org/10.1158/1078-0432.CCR-16-2172

[18] Begicevic, R.R. and Falasca, M. (2017) ABC Transporters in Cancer Stem Cells: Beyond Chemoresistance. International Journal of Molecular Sciences, 18, Article No. 2362. https://doi.org/10.3390/ijms18112362

[19] Garcia-Mayea, Y., Mir, C., Masson, F., Paciucci, R. and Lleonart, M.E. (2020) Insights into New Mechanisms and Models of Cancer Stem Cell Multidrug Resistance. Seminars in Cancer Biology, 60, 166-180. https://doi.org/10.1016/j.semcancer.2019.07.022

[20] Wang, P., Yang, Li, H.L., Yang, Y.J., Wang, L. and Lee, S.C. (2015) Overcome Cancer Cell Drug Resistance Using Natural Products. Evidence-Based Complementary and Alternative Medicine, 2015, Article ID: 767136. https://doi.org/10.1155/2015/767136

[21] Wang, J.Q., Yang, Y., Cai, C.Y., Teng, Q.X., Cui, Q., Lin, J., Assaraf, Y.G. and Chen, Z.S. (2021) Multidrug Resistance Proteins (MRPs): Structure, Function and the Overcoming of Cancer Multidrug Resistance. Drug Resistance Updates, 54, Article ID: 100743. https://doi.org/10.1016/j.drup.2021.100743

[22] Williams, W.R. (2020) Tumour Initiation, Store-Operated Calcium Entry (SOCE) 
and Apoptosis: Cyclic Nucleotide Dependence. General Physiology and Biophysics, 39, 419-435. https://doi.org/10.4149/gpb_2020020

[23] Armstrong, J.F., Faccenda, E., Harding, S.D., Pawson, A.J., Southan, C., Sharman, J.L., Campo, B., Cavanagh, D.R., Alexander, S.P.H., Davenport, A.P., Spedding, M. and Davies, J.A. (2019) NC-IUPHAR The IUPHAR/BPS Guide to Pharmacology in 2020: Extending Immunopharmacology Content and Introducing the IUPHAR/MMV Guide to MALARIA PHARMACOLOGY. Nucleic Acids Research, 48, D1006-D1021. https://doi.org/10.1093/nar/gkz951

[24] Redondo-Bianco, S., Fernandez J., Gutierrez-del-Rio, I., Villar, C.J. and Lombo, F. (2017) New Insights towards Colorectal Cancer Chemotherapy Using Natural Bioactive Compounds. Frontiers in Pharmacology, 8, Article No. 109. https://doi.org/10.3389/fphar.2017.00109

[25] Mao, Q. and Unadkat, J.D. (2015) Role of the Breast Cancer Resistance Protein (BRCP/ABCG2) in Drug Transport-An Update. The AAPS Journal, 17, 65-82. https://doi.org/10.1208/s12248-014-9668-6

[26] Al-Fatlawi, A.A., Al-Fatlawi, A.A., Irshad, M., Zafaryab, M., Rizvi, M.M. and Ahmad, A. (2014) Rice Bran Phytic Acid Induced Apoptosis through Regulation of Bcl-2/Bax and p53 Genes in HepG2 Carcinoma Cells. Asian Pacific Journal of Cancer Prevention, 15, 3731-3716. https://doi.org/10.7314/APJCP.2014.15.8.3731

[27] Liu, G., Liu, Z., Yan, Y. and Wang, H. (2017) Effect of Fraxetin on Proliferation and Apoptosis in Breast Cancer Cells. Oncology Letters, 14, 7374-7378. https://doi.org/10.3892/ol.2017.7143

[28] Raut, N., Wicks, S.M., Lawal, T.O. and Mahady, G.B. (2019) Epigenetic Regulation of Bone Remodeling by Natural Compounds. Pharmaceutical Research, 147, Article ID: 104350. https://doi.org/10.1016/j.phrs.2019.104350

[29] Huang, X., Wu, L., Kuang, Y., Li, X., Deng, X., Liang, X., Li, L., Yang, H., Huang, Z., Lu, D. and Luo, X. (2019) Tauroursodeoxycholic Acid Mediates Endoplasmic Reticulum Stress and Autophagy in Adrenocortical Carcinoma Cells. Oncology Letters, 18, 6475-6482. https://doi.org/10.3892/ol.2019.11057

[30] Yamada, Y., Nakamura, K., Furukawa, R., Kawamura, E., Moriwaki, T., Matsumoto, K., Okuda, K., Shindo, M. and Harashima, H. (2013) Mitochondrial Delivery of Bongkrekic Acid Using a MITO-Porter Prevents the Induction of Apoptosis in Human HeLa Cells. Journal of Pharmaceutical Sciences, 102, 1008-1015. https://doi.org/10.1002/jps.23442

[31] Tian, H., Lu, Y., Shah, S.P., Wang, Q. and Hong S. (2012) 14S,21R-DihydroxyDocosahexaenoic Acid Treatment Enhances Mesenchymal Stem Cell Amelioration of Renal Ischaemia/Reperfusion Injury. Stem Cells and Development, 21, 1187-1199. https://doi.org/10.1089/scd.2011.0220

[32] Orbo, A., Kjorstad, K., Jaeger, R. and Sager, G. (1995) Rapid Non-Genomic and Concentration-Dependent Effects of Progesterone in c4-I Cells on the Proposed Tumor-Marker-Ratio between Extracellular CGMP and cAMP Levels. International Journal of Oncology, 6, 1279-1282. https://doi.org/10.3892/ijo.6.6.1279

[33] Lewis-Wambi, J.S. and Jordan, C.V. (2009) Estrogen Regulation of Apoptosis: How Can One Hormone Stimulate and Inhibit? Breast Cancer Research, 11, Article No. 206. https://doi.org/10.1186/bcr2255

[34] Milner, A.E., Palmer D.H., Hodgkin, E.A., Eliopoulos, A.G., Knox, P.G., Poole, C.J., Kerr, D.J. and Young, L.S. (2002) Induction of Apoptosis by Chemotherapeutic Drugs: The Role of FADD in Activation of Caspase-8 and Synergy with Death Receptors in Ovarian Carcinoma Cells. Cell Death and Differentiation, 9, 287-300. 
https://doi.org/10.1038/sj.cdd.4400945

[35] Ogitani, Y., Aida, T., Hagihara, K., Yamaguchi, J., Ishii, C., Harada, N., Soma, M., Okamoto, H., Oitate, M., Arakawa, S., Hirai, T., Atsumi, R., Nakada, T., Hayakawa, I., Abe Y. and Agatsuma, T. (2016) DS-8201a, a Novel HER2-Targeting ADC with a Novel DNA Topoisomerase 1 Inhibitor, Demonstrates a Promising Antitumor Efficacy with Differentiation from T-DM1. Clinical Cancer Research, 22, 5097-5108. https://doi.org/10.1158/1078-0432.CCR-15-2822

[36] Barok, M., Joensuu, H. and Isola, J. (2014) Trastuzumab Emtansine: Mechanisms of Action and Drug Resistance. Breast Cancer Research, 16, Article No. 209. https://doi.org/10.1186/bcr3621

[37] Lo, Y.L., Wang, W. and Ho, C.T. (2012) 7,3',4'-Trihydroxyisoflavone Modulates Multidrug Resistance Transporters and Induces Apoptosis via Production of Reactive Oxygen Species. Toxicology, 302, 221-232.

https://doi.org/10.1016/j.tox.2012.08.003

[38] Cui, Q., Wang, J.Q., Assaraf, Y.G., Ren, L., Gupta, P., Wei, L., Ashby, C.R., Yang, D.H. and Chen, Z.S. (2018) Modulating ROS to Overcome Multidrug Resistance in Cancer. Drug Resistance Updates, 41, 1-25.

https://doi.org/10.1016/j.drup.2018.11.001

[39] Nicco, C. and Batteux, F. (2018) ROS Modulator Molecules with Therapeutic Potential in Cancers Treatments. Molecules, 23, Article No. 84. https://doi.org/10.3390/molecules23010084

[40] Mohammad, R.M., Muqbil, I., Lowe, L., Yedjou, C., Hsu, H.Y., Lin, L.T., Siegelin, M.D., et al. (2015) Broad Targeting of Resistance to Apoptosis in Cancer. Seminars in Cancer Biology, 35, S78-S103. https://doi.org/10.1016/j.semcancer.2015.03.001

[41] Sheikhpour, M., Sadeghizadeh, M., Yazdian, F., Mansoori, A., Asadi, H., Movafagh, A. and Shahraeini, S.S. (2020) Co-Administration of Curcumin and Bromocriptine Nano-Liposomes for Induction of Apoptosis in Lung Cancer Cells. Iran Biomedical Journal, 24, 24-29. https://doi.org/10.29252/ibj.24.1.24

[42] Xu, S., Luo L., Zhu, L.Q. and Li, Z. (2006) Reversal Effects of 4-Methylether-Scutellarein on Multidrug Resistance in Human Choriocarcinoma of JAR/VP16. Progress in Biochemistry and Biophysics, 33, 1061-1073.

[43] Ji, N., Yang, Y., Cai, C.Y., Wang, J.Q., Lei, Z.N., Wu, Z.X., Cui, Q., Yang, D.H., Chen Z.S. and Kong, D. (2019) Midostaurin Reverses ABCB1-Mediated Multidrug Resistance, an in Vitro Study. Frontiers in Oncology, 9, Article No. 514. https://doi.org/10.3389/fonc.2019.00514

[44] Khare, S., Wilson, D.M., Tien, X.Y., Dudeja, P.K., Wali, R.K., Sitrin, M.D. and Brasitus, T.M. (1993) 1,25-Dihydroxycholecalciferol Rapidly Activates Rat Colonic Particulate Guanylate cyclase via a Protein Kinase C-Dependent Mechanism. Endocrinology, 133, 2213-2219. https://doi.org/10.1210/endo.133.5.8104780

[45] Vasquez, G., Russo de Boland, A. and Boland, R.L. (2000) Involvement of Calmodulin in 1 $\alpha, 25$-Dihydroxyvitamin D3 Stimulation of Store-Operated $\mathrm{Ca}^{2+}$ Influx in Skeletal Muscle Cells. Journal of Biological Chemistry, 275, 16134-16138. https://doi.org/10.1074/jbc.C901008199

[46] Chen, L., Yang, R., Qiao, W., Yuan, X., Wang, S., Goltzman, D. and Miao, D. (2018) 1,25-Dihydroxy Vitamin D Prevents Tumorigenesis by Inhibiting Oxidative Stress and Inducing Tumor Cellular Senescence in Mice. International Journal of Cancer, 143, 368-382. https://doi.org/10.1002/ijc.31317

[47] Jangholi, E., Sharifi, Z.N., Horseinian, M., Zarrindast, M.R., Rahimi, H.R., Mowla, A., Aryan, H., M.A., Javidi, M.A, Parsa, Y., Ghaffarpasand, F., Yadoliah-Damavandi, S., 
Arani, H.Z., Shahi, F. and Movassaghi, S. (2020) Verapamil Inhibits Mitochondria-Induced Reactive Oxygen Species and Dependent Apoptosis Pathways in Cerebral Transient Global Ischemia/Reperfusion. Oxidative Medicine and Cellular Longevity, 2020, Article ID: 5872645. https://doi.org/10.1155/2020/5872645

[48] Trompier, D., Chang, X.B., Barattin, R., Du Moulinet D’Hardemare, A., Di Pietro, A. and Baubichon-Cortay, H. (2004) Verapamil and Its Derivative Trigger Apoptosis through Glutathione Extrusion by Multidrug Resistance Protein MRP1. Cancer Research, 64, 4950-4956. https://doi.org/10.1158/0008-5472.CAN-04-0143

[49] Schultz, C., Vaskinn, S., Kildalsen, H. and Sager, G. (1998) Cyclic AMP stimulates the Cyclic GMP Egression Pump in Human Erythrocytes: Effects of Probenecid, Verapamil, Progesterone, Theophylline, IBMX, Forskolin, and Cyclic AMP on Cyclic GMP Uptake and Association to Inside-Out Vesicles. Biochemistry, 37, 1161-1166. https://doi.org/10.1021/bi9713409

[50] Kondratskyi, A., Yassine, M., Slomianny, C., Kondratska, K., Gordienko, D., Dewailly, E., Lehen'kyi, V., Skryma, R. and Prevarskaya, N. (2014) Identification of ML-9 as a Lysosomotropic Agent Targeting Autophagy and Cell Death. Cell Death and Disease, 5, Article ID: e1193. https://doi.org/10.1038/cddis.2014.156

[51] Wang, Y.W., Zhang, J.H., Yu, Y., Yu J. and Huang L. (2016) Inhibition of StoreOperated Calcium Entry Protects Endothelial Progenitor Cells from $\mathrm{H}_{2} \mathrm{O}_{2}$-Induced Apoptosis. Biomolecules and Therapeutics, 24, 371-379.

https://doi.org/10.4062/biomolther.2015.130

[52] Xu, W., Cheng, Y. and Huirong, Z. (2016) Evaluation of an Association of Blood Homocysteine Levels with Gastric Cancer Risk from 27 Case-Control Studies. Medicine, 95, e3700. https://doi.org/10.1097/MD.0000000000003700

[53] Chang, L., Xu, J.X., Zhao, J., Pang, Y.Z., Tang, C.S. and Qi, Y.F. (2004) Taurine Antagonized Oxidative Stress Injury Induced by Homocysteine in Rat Vascular Smooth Muscle Cells. Acta Pharmacologica Sinica, 25, 341-346.

[54] Johnson, Z.L. and Chen, J. (2017) Structural Basis of Substrate Recognition by the Multidrug Resistance Protein MRP1. Cell, 168, 1075-1085.E9. https://doi.org/10.1016/j.cell.2017.01.041

[55] Zloh, M., Kaatz, G.W. and Gibbons, S. (2004) Inhibitors of Multidrug Resistance (MDR) Have Affinity for MDR Substrates. Bioorganic and Medicinal Chemistry Letters, 14, 881-885. https://doi.org/10.1016/j.bmcl.2003.12.015

[56] Khunweeraphong, N., Mitchell-White, J., Szollosi, D., Hussein, T., Kuchier, K., Kerr, I.D., Stockner, T. and Lee, J.Y. (2020) Picky ABCG5/G8 and Promiscuous ABCG2-A Tale of Fatty Diets and Drug Toxicity. FEBS Letters, 594, 4035-4058. https://doi.org/10.1002/1873-3468.13938

[57] Insel, P.A., Zhang, L., Murray, F., Yokouchi, H. and Zambon, A.C. (2012) Cyclic AMP Is Both a Pro-Apoptotic and Anti-Apoptotic Second Messenger. Acta Physiology, 204, 277-287. https://doi.org/10.1111/j.1748-1716.2011.02273.x

[58] Perez, D.R. Sklar, L.A., Chigaev, A. and Matlawska-Wasowska, K. (2021) Drug Repurposing for Targeting Cyclic Nucleotide Transporters in Acute Leukemias-A Missed Opportunity. Seminars in Cancer Biology, 68, 199-208. https://doi.org/10.1016/j.semcancer.2020.02.004

[59] Binnaz, A., Iyanoye, A., Sieck, G.C., Prakash, Y.S. and Pabelick, C.M. (2005) Cyclic Nucleotide Regulation of Store-Operated $\mathrm{Ca}^{2+}$ Influx in Airway Smooth Muscle. American Journal of Physiology, Lung Cellular and Molecular Physiology, 290, L278-L283. https://doi.org/10.1152/ajplung.00188.2005

[60] Hassanvand, F., Mohammadi, T., Aboubzadeh, N., Tavakoli, A. Hassanzadeh, N. 
Sanikhani, N.S., Azimi, A.I., Mirzaei, H.R., Khodamoradi, M., Goudarzi, K.A, Pourghadamyari, H. and Zaimy, M.A. (2020) Sildenafil Enhances Cisplatin-Induced Apoptosis in Human Breast Adenocarcinoma Cells. Journal of Cancer Research, 16, $1412-1418$.

[61] Muniyan, S., Rachagani, S., Parte, S., Halder, S., Seshacharyulu, P., Kshirsagar P, Siddiqui, J.A., Vengoji, R., Rauth, S., Islam, R., Mallya, K., Datta, K., Lei, X., Das, A., Teply, B.A. Kukreja, R.C. and Batra, S.K. (2020) Sildenafil Potentiates the Therapeutic Efficacy of Docetaxel in Advanced Prostate Cancer by Stimulating NO-cGMP Signaling. Clinical Cancer Research, 26, 5720-5734.

https://doi.org/10.1158/1078-0432.CCR-20-1569

[62] Kashgari, F.K, Ravna, A., Sager, G., Lysa, R., Enyedy, I. and Dietrichs, E.S. (2020) Identification and Experimental Confirmation of Novel cGMP Efflux Inhibitors by Virtual Ligand Screening of Vardenafil-Analogues. Biomedicine and Pharmacotherapy, 126, Article ID: 110109. https://doi.org/10.1016/j.biopha.2020.110109

[63] Shi, Z., Tiwari, A.K., Shukla, S., Robey, R.W., Singh, S., Kim, I.W., Bates, S.E., Peng, X., Abraham, I., Ambudkar, S.V., Talele, T.T., Fu, L.W. and Chen, Z.S. (2011) Sildenafil Reverses ABCB1- and ABCG2-Mediated Chemotherapeutic Drug Resistance. Cancer Research, 71, 3029-3041. https://doi.org/10.1158/0008-5472.CAN-10-3820

[64] Fernandes, M.A.S., Marques, R.J.F., Vicente, J.A.F. Santos, M.S., Monteiro, P. Moreno, A.J.M. and Custodio, J.B.A. (2008) Sildenafil Citrate Concentrations Not Affecting Oxidative Phosphorylation Depress $\mathrm{H}_{2} \mathrm{O}_{2}$ Generation by Rat Heart Mitochondria. Molecular and Cellular Biochemistry, 309, Article No. 77. https://doi.org/10.1007/s11010-007-9645-9

[65] Di Luigi, L., Duranti, G., Antonioni, A. Sgro, P., Ceci, R., Crescioli C., Sabatini, S., Lenzi, A., Caprossi D., Del Galdo, F., Dimauro, I. and Antinozzi, C. (2020) The Phosphodiesterase Type 5 Inhibitor Sildenafil Improves DNA Stability and Redox Homeostasis in Systemic Sclerosis Fibroblasts Exposed to Reactive Oxygen Species. Anitioxidants, 9, Article No. 786. https://doi.org/10.3390/antiox9090786

[66] Wang, J.,Yang, K., Xu, L., Zhang, Y., Lai, N., Jiang, H., Zhang, Y., Zhong, N., Ran, P. and Lu, W. (2013) Sildenafil Inhibits Hypoxia-Induced Transient Receptor Potential Canonical Protein Expression in Pulmonary Arterial Smooth Muscle via cGMP-PKG-PPAR $\gamma$ Axis. American Journal of Respiratory Cell and Molecular Biology, 49, 231-240. https://doi.org/10.1165/rcmb.2012-0185OC

[67] Li, X., Chen, W., Zhang, L., Liu, W.B. and Fei, Z. (2013) Inhibition of Store-Operated Calcium Entry Attenuates $\mathrm{MPP}^{+}$-Induced Oxidative Stress via Preservation of Mitochondrial Function in PC12 Cells: Involvement of Homer1a. PLOS ONE, 8, e83638. https://doi.org/10.1371/journal.pone.0083638

[68] Wang, T., Tsang, S.H. and Chen, J. (2017) Two Pathways of Rod Photoreceptor Cell Death Induced by Elevated cGMP. Human Molecular Genetics, 26, 2299-2306. https://doi.org/10.1093/hmg/ddx121

[69] Guo, Y.S., Tang, J., Chen, B., Huang, W., Li, Y., Cui, H.Y., Zhang, X., Wang, S.J., Chen, Z.N. and Jiang, J.L. (2011) $\beta$ ig-h3 Regulates Store-Operated $\mathrm{Ca}^{2+}$ Entry and Promotes the Invasion of Human Hepatocellular Carcinoma Cells. Cell Biology International, 35, 811-817. https://doi.org/10.1042/CBI20100916

[70] Wong, J.C., Bathina, M. and Fiscus, R.R. (2012) Cyclic GMP/protein kinase G type-1 $\alpha$ (PKG-1 $\alpha$ ) Signalling Pathway Promotes CREB Phosphorylation and Maintains Higher c-1AP1, Livin, Surviving, and Mcl-1 Expression and the Inhibition of PKG-1 $\alpha$ Kinase Activity Synergizes with Cisplatin in Non-Small Cell Lung Cancer cells. Journal of Cell Biochemistry, 113, 3587-3598. 
https://doi.org/10.1002/jcb.24237

[71] Suganya, N., Mani, K. P., Sireesh, D., Rajaguru, P., Vairamani, M., Suresh, T., Suzuki, T., Chatterjee, S. and Ramkumar, K.M. (2018) Establishment of Pancreatic Microenvironment Model of ER Stress: Quercetin Attenuates $\beta$-Cell Apoptosis by Invoking Nitric-Oxide-cGMP Signaling in Endothelial Cells. Journal of Nutritional Biochemistry, 55, 142-156. https://doi.org/10.1016/j.jnutbio.2017.12.012

[72] Jeong, S.O., Son, Y., Lee, J.H., Choi, S.W., Kim, S.K., Cheong, Y.K., Chung, H.T. and Pae, H.O. (2017) Both Nitric Oxide and Nitrite Prevent Homocysteine-Induced Endoplasmic Reticulum Stress and Subsequent Apoptosis via cGMP-Dependent Pathway in Neuronal Cells. Biochemical and Biophysical Research Communication, 493, 164-169. https://doi.org/10.1016/j.bbrc.2017.09.054

[73] Seya, K., Ono, K., Fujisawa, S., Okumura, K., Motomura, S. and Furukawa, K.I. (2013) Cytosolic $\mathrm{Ca}^{2+}$-Induced apoptosis in Rat Cardiomyocytes via Mitochondrial NO-cGMP-Protein Kinase G Pathway. The Journal of Pharmacology and Experimental Therapeutics, 344, 77-84. https://doi.org/10.1124/jpet.112.198176 